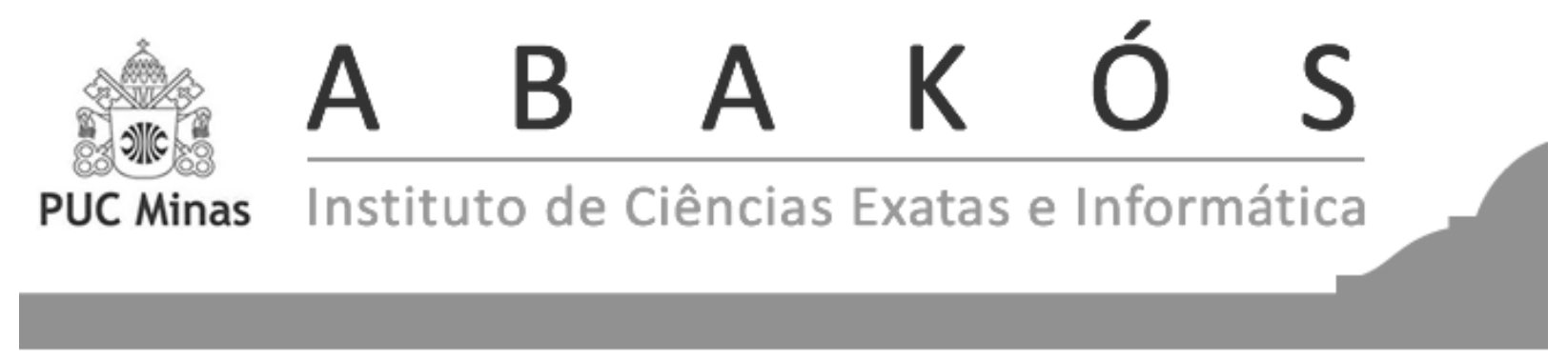

\title{
Uma visão interdisciplinar do ensino de ciências por meio do teatro científico*
}

An interdisciplinary vision of science teaching through scientific theatre

\author{
Roseana da Silva Bezerra ${ }^{1}$ \\ Leonardo Alcântara Alves ${ }^{2}$ \\ Albino Oliveira Nunes ${ }^{3}$
}

\begin{abstract}
Resumo
Discutir interdisciplinaridade, na escola, é sempre um desafio. É necessário compreender a sua importância real na formação do aluno como cidadão, e como se pode abordá-la para contribuir na referida formação. O presente trabalho tem como objetivo discutir esses pontos, mediante uma ferramenta de ensino usada por professores de ciências, chamada "Teatro Científico". Em uma pesquisa qualitativa, realizou-se uma entrevista semiestruturada com três professores de Química que usam essa ferramenta em diferentes escolas de ensino médio na cidade de Mossoró, no Rio Grande do Norte, questionando como a interdisciplinaridade é abordada nesses projetos, e como essa ferramenta pode contribuir para o ensino e para a formação cidadã dos alunos envolvidos nos projetos. Por meio da análise de conteúdo, foi possível perceber que o trabalho com o Teatro Científico possibilita a aplicação de uma abordagem interdisciplinar. Ressalta-se, também, a contribuição com a formação crítica do aluno, já que ele ou ela exercita diversas habilidades cognitivas, como trabalho em grupo, solidariedade, compromisso e responsabilidade. Apesar disso, várias dificuldades foram percebidas ao se trabalhar com essa ferramenta, nas escolas, devido à falta de cooperação de outros professores. Isso acontece, de acordo com os professores, com qualquer atividade interdisciplinar. Segundo eles, isso é resultado da falta de tempo e de motivação dos professores para o planejamento de tais atividades, devido ao trabalho em outras instituições, baixos salários, fadiga e outros fatores.
\end{abstract}

Palavras-chave: Interdisciplinaridade. Teatro científico. Ensino de Ciências.

\footnotetext{
* Submetido em 13/08/2017 - Aceito em 06/08/2018

${ }^{1}$ Mestranda em Ensino, pelo Programa de Pós-graduação em Ensino (POSENSINO), Brasilrosydasylva@hotmail.com

${ }^{2}$ Professor orientador do Programa de Pós-graduação em Ensino (POSENSINO), Brasilleonardo.alcantara@ifrn.edu.br

${ }^{3}$ Professor orientador do Programa de Pós-graduação em Ensino (POSENSINO), Brasil- albino.nunes@ifrn.edu.br
} 


\begin{abstract}
Discussing interdisciplinarity at school is always a challenge. It is necessary to understand its real importance in the formation of the student as a citizen, and how it can be approached to contribute in this formation. The present work aims to discuss these points using a teaching tool that is being used by science teachers, called "Scientific Theater". In a qualitative investigation, an interview was conducted with three chemistry teachers who use this tool in different high schools in Mossoró City, RN, Brazil, questioning how the interdisciplinarity is approached in these projects and how this tool can contribute to the teaching and citizen formation of the students involved in the project. Through the content analysis, it was noted that when working the scientific theater, it is possible that interdisciplinarity can cover a higher number of disciplines. It is also emphasized the contribution in the student critical formation, since he or she exercises several cognitive abilities like group work, solidarity, commitment and responsibility. Despite this, there is several difficulties when working this tool in schools due to lack of cooperation of other teachers. This happens, according to the teachers, with any interdisciplinary activity. This, according to them, is a result of the lack of time and motivation of teachers to plan such activities due to work in other jobs, low wages, fatigue and other.
\end{abstract}

Keywords: Interdisciplinarity. Scientific theater. Science teaching. 


\section{INTRODUÇÃO}

Realizar pesquisas sobre interdisciplinaridade e qualidade de ensino tem sido cada vez mais a preocupação dos pesquisadores na área de ensino e de educação. Isso se dá devido aos grandes debates que ainda permeiam esses temas como, por exemplo, o tipo de abordagem para se trabalhar interdisciplinarmente e como melhorar a qualidade de ensino nas escolas públicas. Sabe-se que não existe uma fórmula ou metodologia específicas para isto. O que se tem feito, e acredita-se ser o caminho certo, é buscar novas metodologias de ensino que possam atender a essas questões. Tratando-se da interdisciplinaridade, um ponto que se percebeu foi a busca por muitos autores em tentar definir ou conceituar o que seria o ensino interdisciplinar. Autores especializados no assunto como Lopes (2005), Thiesen (2013), Fazenda (2011) e outros concordam que não existe um conceito fechado ou uma definição fixa, pois a interdisciplinaridade seria tudo aquilo que procura integrar o ensino ou que vai além das disciplinas compartimentalizadas, ou seja, não há uma metodologia fixa ou um tipo de ensino interdisciplinar. Nessa perspectiva, destaca-se o que expressam Moran, Masetto e Behrens (2000, p. 23) ao pontuarem que a vivência, a experimentação e os sentimentos são importantes para o aprendizado, além dos vínculos e das relações que se fazem entre o novo conhecimento e a integração desse em um contexto, de modo a lhe dar sentido (LOPES, 2005; THIESEN, 2013; FAZENDA, 2011; MORAN et al., 2000).

Neste trabalho, essa integração de disciplinas e as vivências são consideradas muito importantes para uma educação de qualidade, pois, além da integração dos conteúdos disciplinares, a contextualização desses com as experiências dos alunos proporcionam, em uma visão pessoal, uma excelente relação entre a educação e a qualidade de ensino. Também se acredita que alunos que tenham a oportunidade de vivenciar um ensino interdisciplinar se sintam mais motivados e capazes em termos de atitudes frente a algumas problemáticas do dia a dia, visto que, além dos conteúdos estarem melhor articulados, a relação e contextualização com o cotidiano se fazem complementos nessa formação.

Cada vez mais se sente a necessidade de investir em novos métodos de ensino que propiciem uma educação ou formação mais completa para o aluno do ensino básico. No ensino de ciências da natureza, percebe-se uma necessidade ainda maior, visto que é comum ouvir dos alunos que o ensino de disciplinas como química e física, por exemplo, são chatas, difíceis e cansativas. Isso resulta na necessidade de trabalhar metodologias que mudem essa concepção. Observa-se que o investimento no uso do lúdico para o ensino destas disciplinas é cada vez mais avaliado como técnica relevante.

Para Garcez (2014), o lúdico remete à diversão e ao prazer associados a brincadeiras enquanto que a função educativa é aquela que utiliza o ensino de algo, fazendo o indivíduo sentir-se completo e com maior compreensão do mundo em que vive. Sendo assim, por que não unir as duas coisas? O ensino e o lúdico. No Teatro Cietífico (TC), procura-se a união equilibrada entre as duas ações, pois, se houver desequilíbrio por parte do lúdico ou do ensino, a associação perde seu sentido. É importante mencionar o quanto atividades como o TC con- 
tribuem para o desenvolvimento da cultura científica (SARAIVA et al., 2007; GARCEZ et al., 2014).

Existem muitos grupos de TC nas universidades, nos cursos de licenciatura em ciências exatas, como Química e Física. Porém, acredita-se que, no ensino médio, essa é uma ferramenta que pode muito bem ser aproveitada, visto que os próprios alunos seriam os envolvidos nos espetáculos. Com esse envolvimento, além do aprendizado conteudista em si, acredita-se que, no teatro, o aluno é capaz de desenvolver várias habilidades importantes para sua formação como, por exemplo, respeito para com os colegas e responsabilidades grupais. Essas observações são discutidas por Moreira e Rezende (2007) ao mencionarem que o jogo teatral no ensino de ciências, além de humanizar a ciência, favorece o trabalho em equipe e a aprendizagem colaborativa. Outro fator que se acredita ser melhorado é a perda da timidez, considerando-se as atividades de oficinas que podem ser desenvolvidas no teatro bem como o desenvolvimento da relação de confiança e intimidade entre os alunos participantes. Francisco Junior et al. (2014) citam essa relação de confiança e de todos os sentimentos contraditórios que podem surgir no decorrer da interação grupal e que acabam por influenciar o meio social dos alunos, sugerindo que "esse efeito social e pertencimento ao grupo podem ser fatores que ajudam a lidar com sentimentos de ansiedade, vergonha, timidez, favorecendo a desinibição com o público" (FRANCISCO JUNIOR et al., 2014, p. 87) (MOREIRA; REZENDE, 2007).

Sendo assim, esse trabalho teve o objetivo de conhecer melhor como se dá a metodologia de trabalho em alguns grupos de TC no ensino médio na cidade de Mossoró - RN e verificar se os professores que trabalham com esta metodologia de ensino têm observado a questão da interdisciplinaridade em seus projetos.

\section{REFERENCIAL TEÓRICO}

\subsection{Interdisciplinaridade: teorias e interpretações}

Ainda se percebem alguns desencontros de ideias ou confusões por parte dos professores sobre o que viria a ser uma atividade interdisciplinar. Alguns falam que a simples contextualização do conteúdo com o cotidiano do aluno já é interdisciplinaridade. Apesar de Fazenda (2011) destacar a importância de contextualizar, ao afirmar que isso é fundamental para o conhecimento, sabe-se que isto não é suficiente. Ao buscar abordar interdisciplinaridade neste texto, não se pretende dar uma definição ou um conceito quanto a esse tema, pois como se tem visto nos atuais estudos, não existe uma definição fixa para o termo. O que se pretende aqui é, por meio dos estudos, chegar a um entendimento particular de como essa abordagem acontece em um projeto de TC na visão dos professores que atuam com esses projetos (FAZENDA, 2011).

Para falar sobre interdisciplinaridade, é preciso lembrar que este é um termo que vem sendo discutido nos mais diferentes âmbitos da educação e por diversos autores. Sendo assim, sentiu-se a necessidade de conhecer como alguns autores e estudiosos do tema abordam 
a interdisciplinaridade no ambiente escolar. No livro "Teorias do Currículo", Lopes e Macedo (2011) tratam a interdisciplinaridade pela integração curricular com base nas disciplinas acadêmicas, valorizando-as individualmente em suas inter-relações, nas quais essas se fazem a partir das disciplinas e não pela sua superação. As autoras reforçam a importância das disciplinas para que haja o processo interdisciplinar. Não propõem acabar com as mesmas, ou com suas individualidades, pois este caráter individual também é importante. A ideia é que haja uma interação maior entre as mesmas, uma integração (LOPES; MACEDO, 2011). Quando se fala em ações de grupos e contextos, existe uma necessidade de ressaltar a importância do trabalho grupal dos professores em prol dessas ações interdisciplinares, se distanciando da ideia de interdisciplinaridade por um único professor.

Thiesen (2013, p. 593) aponta que a interdisciplinaridade não tem um conceito definido e tentar defini-la é muito difícil pelo fato de que ainda está sendo construída. O autor aponta três pontos importantes que podem ser vistos como interdisciplinaridade: a primeira que está situada no educador enquanto sujeito principal, nos materiais didáticos que podem ser utilizados e as ações grupais com foco interdisciplinar. Outro ponto importante é o fato de que a interdisciplinaridade pode ser vista como sendo toda a bagagem de aprendizagem que o aluno adquire em toda sua vida, seja ela, cultural, histórica ou social. Fazenda (2011) ressalta a importância do trabalho interdisciplinar e que não se pode fazer só por fazer ou por exigência da escola. É importante ter em mente que esse trabalho exige muito estudo e planejamento para que se possa aplicá-lo e, além disso, reconhecer como tem se dado esta aplicação na perspectiva de que a interdisciplinaridade é uma questão de atitude. O autor realça que é preciso haver uma "sintonia" entre os professores e reciprocidade também, ou seja, vontade de trabalhar com conjunto, resultando em uma verdadeira mudança no comportamento destes professores (THIESEN, 2013; FAZENDA, 2011).

Tratando das mais diversas ideias dos autores aqui citados, destaca-se Thiesen (2013) que trata essas discussões como essencial à ideia de superação da fragmentação das ciências como um todo e do ensino produzido por elas. Aqui, se busca ir além do conceito da interdisciplinaridade, pois acredita-se ser mais importante entender qual o seu sentido no processo de aprendizagem. Muitos professores tentam trabalhar de maneira interdisciplinar, superando essa fragmentação da ciência e buscam incentivar seus colegas a também tomar essa atitude, pois veem a prática como uma ação transformadora que não se dá só no ensino, mas também da formação do aluno enquanto ser social. Muitas intervenções interdisciplinares que acontecem nas escolas são por meio de projetos, feiras de ciências, estudos grupais e outras atividades que acontecem com as participações de vários professores que trabalham de forma interdisciplinar e em grupo. Nessa linha, acredita-se que os projetos são uma forma bastante eficaz de se trabalhar a interdisciplinaridade (THIESEN, 2013).

Para Lück (1994), estas práticas interdisciplinares promovem a superação da visão restrita do mundo ao mesmo tempo em que resgata a centralidade do homem na produção do seu próprio conhecimento. $\mathrm{O}$ autor acredita que, ao identificar o homem como ser determinante e determinado, pensa-se nele como um sujeito atuante na sociedade, alguém que seja capaz de 
decidir, opinar, criticar, aprender e intervir no meio em que vive. Defende-se, aqui nesta pesquisa, a utilização da interdisciplinaridade no sentido de fazer dos alunos os próprios sujeitos do seu aprendizado por meio de atividades que envolvam temas importantes para o meio em que vivem, que os façam buscar por esses conhecimentos e que, assim, contribuam também para sua formação enquanto cidadão (LÜCK, 1994).

\subsection{A interdisciplinaridade e a qualidade de ensino na formação do cidadão}

Pretende-se, nesta seção, esclarecer a importância da formação do educando de modo que esse possa, além de ser formado para o mercado de trabalho, ter um pensamento reflexivo e crítico, que seja um formador de opiniões, conheça seus direitos e deveres perante à sociedade. Para isto, defende-se a formação interdisciplinar, em que, além de se utilizar das disciplinas de forma "isoladas", se possa também trabalhar de forma integrada, visto que se acredita que essa é uma excelente maneira de inserir o educando na realidade da sociedade em que ele vive.

Paro (2007) afirma que a função da escola não é limitada ao fornecimento de informações aos alunos para prepará-los para o mercado de trabalho ou para vestibulares. Para o autor, a escola deve se apropriar de cultura, tendo sua base em questões que envolvam valores, crenças, artes, filosofia e ciência. Novamente, ressalta-se a importância da formação desses educandos enquanto cidadãos para viverem em sociedade e na importância da escola nessa ação (PARO, 2007).

Além disso, deve-se ter um olhar mais direcionado para a importância da bagagem histórica que os alunos carregam consigo. Tudo o que eles aprendem e adquirem em suas vivências são importantes para sua formação. Percebe-se que o significado de qualidade de ensino vai além da aprendizagem de conteúdos, mas trata-se da capacitação do indivíduo para viver em sociedade e da relação dos conteúdos com essa capacitação. Freire (2002, p. 25) já discutia a importância de respeitar a autonomia, a dignidade e a identidade do educando visto que, sem essas, o conhecimento não teria o valor necessário, tornando-se inoperante, vazio (FREIRE, 2002).

Fazenda (2011) traz um fato importante que é preciso ser lembrado, que a interdisciplinaridade não é uma panaceia que dá garantia a um ensino adequado e saber unificado, mas sim um ponto de vista que leva a uma reflexão aprofundada e crítica sobre o funcionamento do mesmo. De fato, não se espera da interdisciplinaridade o peso de por si só transformar o ensino, mas se vê aqui uma ferramenta de apoio ao ensino das ciências como um todo. Vê-se a substituição de uma concepção fragmentada por uma concepção única de conhecimento, dando um significado maior ao desenvolvimento de cada aluno, permitindo-lhe desenvolver suas atividades, assegurando seu papel na sociedade. Teixeira (2007) assume a interdisciplinaridade como uma abordagem suscetível de fazer duas ou mais disciplinas interagirem entre si por meio de uma simples comunicação de ideias ou uma interação mútua dos conceitos, facilitando a comunicação entre os conteúdos, entre os saberes, entre a realidade em que vivemos, proporcionando, 
assim, uma formação mais ampla aos alunos. (FAZENDA, 2011; TEIXEIRA, 2007)

Acredita-se que não basta estudar e adquirir conhecimentos. É preciso aplicar estes conhecimentos no meio em que o aluno está inserido, fazendo-o participar ativamente do meio em que vive. Luck (1994) afirma que, até hoje, o que se busca é quebrar o ensino fragmentado que muitas vezes não faz sentido ao aluno, que não consegue ver como esses conhecimentos podem ser aplicados no seu dia a dia separadamente. Busca-se uma maior interação entre docentes e disciplinas do currículo com a realidade do aluno, proporcionando, assim, uma formação integral (LÜCK, 1994).

Isto confirma o fato de que é o trabalho em conjunto de professores que pode fazer a diferença nessa forma interdisciplinar de ensinar e na qualidade do ensino. Moran, Masetto e Behrens (2000) diferenciam ensino de qualidade de educação de qualidade. Para eles, o ensino trata de atividades didáticas que ajudam o aluno a compreender determinadas áreas do conhecimento como ciências, história, matemática e outras. A educação, além de ensinar, ajuda a unificar o ensino e a vida, proporcionando noções sobre ter conhecimento e ética, reflexão e ação, e a traçar um caminho intelectual, emocional e profissional que o realize e o faça contribuir para modificar a sociedade em que vive. Essa visão dos autores faz perceber que a qualidade de ensino está diretamente ligada com a formação do aluno enquanto cidadão. Santos e Mortimer (1999) elencam ainda que, para alcançar a formação para cidadania, é essencial a discussão relativa às "dimensões sociais, ambientais, tecnológicas, políticas, éticas e econômicas do conhecimento científico no ensino médio" (SANTOS; MORTIMER, 1999, p.1). Santos (2011) trata a educação para a cidadania a partir da educação que leva a tomada de decisões ressaltando a necessidade de desenvolver nos alunos a "faculdade de julgar" (p. 302) (SANTOS, 2011).

\subsection{Teatro científico como proposta metodológica no ensino de ciências}

É fato que a prática interdisciplinar tem se tornado cada vez mais uma exigência dentro da educação brasileira, porém, a insegurança e a dificuldade de realizar projetos dessa natureza ainda imperam entre os educadores (FAZENDA, 2002). Moreira (2013, p. 39) destaca a complexidade quanto à inserção de novos métodos de ensino ou, como por ele chamado, "um novo conhecimento". O autor destaca que essa inserção passa por um complexo de transposição no qual o conhecimento a ser transposto deve atender algumas características, como, consensualidade, atualidade, criatividade didática, entre outros, além de modernizar o saber escolar e propiciar a articulação do novo saber com o antigo. Dentre as metodologias que podem propiciar essa educação, ressaltam-se os jogos, olimpíadas, feiras de ciências, teatro, e outras abordagens que são excelentes instrumentos para tal proposição (MOREIRA, 2013).

Acredita-se que, dependendo da metodologia abordada ou da ferramenta de ensino utilizada, é possível trabalhar projetos, aulas, ou atividades de campo que possam ser abordadas de forma interdisciplinar e ainda fazer uso de metodologias alternativas no ensino, resultando no 
aumento do interesse dos alunos pelo estudo. O TC seria uma destas alternativas que possibilitam esse ensino interdisciplinar e o interesse dos alunos pelo conteúdo a ser ministrado. Muitas vezes, o professor tem dificuldade de realizar práticas ou projetos interdisciplinares devido à sua formação "positivista e fragmentada" segundo Kleiman e Morais (1999). Ainda segundo essas mesmas autoras, os professores não se sentem seguros ao realizar essa tarefa, acham que não dão conta, e que não conseguem pensar interdisciplinarmente (KLEIMAN; MORAES, 1999).

O TC, como supracitado, é uma ferramenta capaz de despertar nos alunos o interesse em estudar ciência bem como a possibilidade de se trabalhar de forma interdisciplinar vários conteúdos, como português, história, sociologia e a ciência como um todo por meio de uma vertente pedagógica. Tratando do TC, Saraiva (2007) ressalta que esse pode se dar por uma exposição de ideias, a narração de um fato histórico dentro da ciência e outras atividades. $\mathrm{O}$ autor ainda afirma que, quando apresentado em escolas, há uma preocupação na abordagem de temas pedagógicos que busquem transmitir conceitos científicos, muitas vezes complicados para os estudantes, de forma lúdica, simples e agradável, provocando, posteriormente, a discussão do conteúdo na sala de aula, bem como o uso de temas sociais importantes, como preconceitos, violência e drogas. Moreira (2013, p. 58) afirma que os espetáculos do TC tratam de forma mais lúdica e agradável questões que discutem conceitos científicos, tornando-as mais acessíveis para o contexto de sala. Essas estratégias metodológicas do TC visam contribuir para a melhoria do processo de ensino e aprendizagem e usar o lúdico como alternativa metodológica requer muito planejamento e atenção por parte dos alunos. Garcez (2014), em sua dissertação, traz essa visão de uma forma bem clara (SARAIVA et al., 2007; MOREIRA, 2013; GARCEZ et al., 2014).

Vale novamente destacar que o lúdico no TC não deve proporcionar apenas brincadeiras aos alunos, mas, aprendizado também, visto que serão trabalhados conteúdos ou fatos históricos das ciências, bem como outras disciplinas, atingindo, além dos estudantes, toda a comunidade, levando a ciência a todos e, de certa maneira, contribuindo um pouco com o entendimento científico do público que assiste à peça de TC. Esse ponto é discutido por Saraiva (2007) ao ver no TC uma possibilidade de cativar e ampliar o público alvo, que, nesse caso, vai além dos alunos. O público se torna a comunidade em geral, constituindo uma ferramenta que vai além do ensino e possibilitando popularizar, comunicar, difundir, divulgar, entre outros termos utilizados para definir atividades como esta.

A aquisição de responsabilidades e habilidades importantes para a formação do aluno é ressaltada nas palavras que Saraiva (2007, p. 22) relata serem desenvolvidas pelos alunos no teatro como "viver e a trabalhar em conjunto com o seu semelhante, a respeitar os outros, a respeitar os seus compromissos, a cumprir regras e a ter disciplina (horário, fidelidade ao texto)". Esse é um dos pontos que se acredita ser muito importante no uso do TC, pois essas habilidades e responsabilidades devem fazer parte da formação do aluno como cidadão vivendo em sociedade. Moreira e Marandino (2013, p. 3) discutem ainda que, "em síntese, a proficuidade da relação Teatro e Ciência residiria na possibilidade de se conhecer a ciência para além dos seus conceitos ou experimentos, focalizando uma abordagem mais humanista". Essa seria uma ma- 
neira de aproximar o público em geral das ciências, favorecendo a compreensão ou indagações frente a um fato histórico ou conteúdo científico, tecnológico, social e político (SARAIVA et al., 2007; MOREIRA; MARANDINO, 2013).

Diante desse estudo, buscou-se, com esse trabalho, conhecer as metodologias abordadas nos grupos de TC em algumas escolas de ensino médio na cidade de Mossoró - RN. Esta avaliação tem como enfoques principais a interdisciplinaridade nas abordagens de cada projeto de TC na visão dos professores que atuam com esses projetos, além de tentar entender como a ciência é abordada por esses grupos, e como o teatro científico influencia na qualidade de ensino dos alunos envolvidos nos projetos, na visão particular de cada docente.

\section{METODOLOGIA}

Inicialmente, foi realizado um mapeamento junto à $12^{\circ}$ Diretoria Regional de Educação Cultura e Esportes (DIRED) na cidade de Mossoró, no Rio Grande do Norte, para avaliar quais as escolas que trabalham com TC. As DIRED's mantêm registro de todas as escolas em suas circunscrições. No caso da $12^{\circ}$ DIRED, situada em Mossoró, a circunscrição abrange os municípios de Areia Branca, Baraúna, Grossos, Governador Dix-sept Rosado, Tibau, Serra do Mel, Upanema e Mossoró. Como a pesquisa ocorre no município de Mossoró, atentou-se apenas às escolas desta região. Sendo assim, solicitou-se o registro dessas escolas a $12^{\circ}$ DIRED, tendo acesso a uma planilha com todas as escolas e seus respectivos telefones. Feito isso, entrou-se em contato com cada escola para saber se existia alguma que trabalhava com TC. Na cidade de Mossoró, encontrou-se um total de 56 instituições, das quais, em apenas três, existiam grupos de TC. Feita essa identificação, entrou-se em contato com os professores responsáveis por sua realização para dar prosseguimento à pesquisa.

O trabalho se deu com base em uma investigação qualitativa que, segundo Bogdan e Biklen (1994), pode ser abordada de diversas formas e em diversos contextos. A expressão "investigação qualitativa" agrupa diversas estratégias de investigação que partilham determinadas características: os dados recolhidos são qualitativos, as questões investigadas não se estabelecem por meio de operacionalização de variáveis, e tem o objetivo de investigar fenômenos em toda a sua complexidade. O que se pretendeu com essa abordagem foi conhecer, na visão dos professores envolvidos com TC, como se desenvolvem os projetos que eles realizam no sentido de promoção de uma ação interdisciplinar. Godoy (1995) afirma a importância de "captar" o fenômeno a partir das perspectivas de quem está envolvido, considerando seus pontos de vista. Já Ludke e André (1986) tratam do material desse tipo de pesquisa como sendo rico em descrições tanto de pessoas como de situações ou acontecimentos, incluindo transcrições de entrevistas e de depoimentos, fotografias, desenhos, e análise de vários tipos de documentos. (BOGDAN et al., 1994; GODOY, 1995; LUDKE; ANDRÉ, 1986) 


\subsection{As entrevistas}

Nesta pesquisa, foi utilizado o método de entrevista semi-estruturada. Segundo Ludke e André (1986, p. 33), a entrevista se destaca por ser uma das principais técnicas de coleta de dados utilizadas em pesquisas das ciências sociais. Permite correções, esclarecimentos e adaptações que podem agregar mais informações à pesquisa, diferentemente de um questionário aplicado, no qual não se tem esclarecimentos nem conversação com o pesquisador, e é usada para recolher dados descritivos na linguagem do próprio sujeito, permitindo aos investigados entender intuitivamente como o sujeito entrevistado interpreta os aspectos do mundo ou o tema abordado (LUDKE; ANDRÉ, 1986).

A entrevista foi realizada com três professores que trabalham com TC. O instrumento se tratava de seis questões subjetivas, apresentadas a seguir: 1) O que é qualidade de ensino? 2) Tratando-se de uma abordagem de qualidade de ensino, onde se trata não apenas de transmissão de conteúdos, mas da formação da personalidade do educando, bem como da preparação desse para viver em sociedade, como você vê a ação do TC nessa qualidade de ensino? 3) Qual a sua visão quanto interdisciplinaridade? 4) Como a interdisciplinaridade pode influenciar a qualidade de ensino? 5) O projeto de TC tem objetivo e/ou abordagens interdisciplinares? 6) Quais as dificuldades de se trabalhar interdisciplinaridade no TC?

As entrevistas duraram entre 40 minutos e 1 hora e os dados foram registrados tanto por gravação direta, utilizando um gravador, quanto com anotações por parte do entrevistador. As entrevistas foram transcritas e os resultados analisados por meio da análise de conteúdo, que é considerada uma das técnicas mais utilizadas para esse tipo de pesquisa.

\subsection{Análise da entrevista}

Análise de conteúdo, segundo Bardin (1997), trata de um conjunto de técnicas utilizadas em análises de comunicações e/ou mensagens, que visam obter a descrição sistemática dos conteúdos dessas, permitindo inferências por parte do pesquisador. Essa técnica é conhecida por proporcionar ao autor da pesquisa analisar o que está explícito no texto por meio de indicadores que o permita fazer induções. A análise de conteúdo se organiza em três momentos: Pré-análise, Exploração do material e Tratamento dos resultados (BARDIN, 1997).

\section{RESULTADOS E DISCUSSÕES}

Realizou-se essa análise em três estágios: primeiro escolheu-se o documento a ser analisado, que, nesse caso, foram as respostas das entrevistas realizadas com os professores; em seguida, ocorreu a formulação de hipóteses quanto às respostas encontradas; logo, houve a elaboração de indicadores que servem como base para fundamentar a construção do quadro por 
meio de categorias, subcategorias, unidades de registro e unidades de contexto. Todo esse processo foi feito pela interpretação da pesquisadora quanto à análise de conteúdo, segundo Bardin (1997; 2011), que envolve uma leitura apenas para conhecer o texto a ser analisado e, em seguida, realizando-se uma leitura na qual identificou-se alguns pontos em comum na fala dos professores, como, palavras e características quanto ao TC. Esse último processo ocorre pela exaustão das respostas, pertinência quanto aos objetivos da pesquisa e exclusividade, sendo que um elemento ao ser identificado para uma categoria, não pode ser repetido. As entrevistas gravadas foram transmitidas integralmente e as gravações conservadas. A organização do material foi feita em forma de colunas, com espaços vazios à esquerda e à direita para anotar e marcar as semelhanças e contrastes encontrados durante a análise, isso, é claro, dependendo do interesse do pesquisador e de seus objetivos (BARDIN, 2011, 1997).

\subsection{Interdisciplinaridade e qualidade de ensino no TC na visão dos professores}

Após avaliação das entrevistas e, de acordo com a análise de conteúdo, inicialmente se fez uma leitura prévia para então aprofundar a análise. Feito isso, elaborou-se um quadro (Quadro 1) com os principais temas e categorias discutidos pelos professores, além de alguns de seus relatos quanto ao tema, para então se fazer uma discussão dessas categorias e relatos. 
Quadro 1 - Entrevista com professores quanto à interdisciplinaridade e qualidade de ensino no TC

\begin{tabular}{|c|c|c|c|}
\hline CATEGORIA & SUBCATEGORIA & $\begin{array}{l}\text { UNIDADE DE } \\
\text { REGISTRO }\end{array}$ & $\begin{array}{c}\text { UNIDADE DE } \\
\text { CONTEXTO }\end{array}$ \\
\hline $\begin{array}{l}\text { Qualidade de } \\
\text { ensino }\end{array}$ & Conteúdo & $\begin{array}{l}\text { le ciências; } \\
\text { - Enem e Feiras } \\
\text { - Relação conteúdo } \\
\text { com o cotidiano, } \\
\text { promovendo o } \\
\text { conhecimento } \\
\text { consciente do } \\
\text { aluno. }\end{array}$ & $\begin{array}{l}\text { Prof. 1: "Você percebe } \\
\text { que a qualidade do } \\
\text { ensino tem aumentado } \\
\text { a partir dos resultados } \\
\text { da escola no Enem e nas } \\
\text { feiras de ciências com } \\
\text { boas apresentações } \\
\text { dos alunos". } \\
\text { Prof. 2: "Qualidade de } \\
\text { ensino para mim é } \\
\text { quando o aluno tem } \\
\text { consciência do seu } \\
\text { aprendizado, e o usa } \\
\text { para tomar decisões e } \\
\text { formar opiniões". } \\
\text { Prof. 3: "Percebemos } \\
\text { que há qualidade de } \\
\text { ensino, quando temos } \\
\text { bons resultados no } \\
\text { Enem e quando os } \\
\text { alunos conseguem } \\
\text { assimilar o conteúdo } \\
\text { com seu cotidiano". }\end{array}$ \\
\hline
\end{tabular}




\begin{tabular}{|c|c|c|c|}
\hline & $\begin{array}{l}\text { Formação quando } \\
\text { cidadão }\end{array}$ & $\begin{array}{l}\text { - Projetos } \\
\text { educacionais que } \\
\text { promovam uma } \\
\text { formação acadêmica } \\
\text { e cidadã; } \\
\text { - Depende de todos } \\
\text { da escola, da família } \\
\text { do aluno e dele } \\
\text { próprio. }\end{array}$ & $\begin{array}{l}\text { Prof. 1: "A relação } \\
\text { professor e aluno é } \\
\text { importante, o aluno } \\
\text { também deve querer } \\
\text { aprender". } \\
\text { Prof. 2: "O envolvimento } \\
\text { de toda a escola, } \\
\text { comunidade e família } \\
\text { do aluno reflete nessa } \\
\text { qualidade de ensino". } \\
\text { Prof. 3: "As feiras de } \\
\text { ciências, projetos que } \\
\text { envolvam temáticas } \\
\text { ambientais, e outros } \\
\text { temas, contribuem para a } \\
\text { formação do aluno quanto } \\
\text { cidadão, já que ele tem a } \\
\text { oportunidade de refletir } \\
\text { sobre determinados } \\
\text { assuntos". }\end{array}$ \\
\hline \multirow[t]{2}{*}{ Interdisciplinaridade } & Trabalho em equipe & $\begin{array}{l}\text { - Aulões, projetos } \\
\text { educacionais, aulas } \\
\text { de campo, "aulas } \\
\text { casadas"; }\end{array}$ & $\begin{array}{l}\text { Prof. 1: "Por mais que o } \\
\text { professor tente } \\
\text { interdisciplinarizar em } \\
\text { suas aulas puxando } \\
\text { assuntos de outras } \\
\text { disciplinas, o conteúdo } \\
\text { fica quebrado". } \\
\text { Prof. 2: "O trabalho e } \\
\text { planejamento de aulas por } \\
\text { dois ou mais professores } \\
\text { dão sentido a } \\
\text { interdisciplinaridade". }\end{array}$ \\
\hline & Enem & $\begin{array}{l}\text { - A importância da } \\
\text { abordagem se reflete } \\
\text { no Enem. }\end{array}$ & $\begin{array}{l}\text { Prof. 3: "Hoje o professor } \\
\text { se vê obrigado a trabalhar } \\
\text { com os outros professores } \\
\text { de forma interdisciplinar } \\
\text { por causa do Enem, e não } \\
\text { por que querem". }\end{array}$ \\
\hline
\end{tabular}




\begin{tabular}{|c|c|c|c|}
\hline $\begin{array}{l}\text { Interdisciplinaridade } \\
\text { e qualidade de } \\
\text { ensino }\end{array}$ & $\begin{array}{l}\text { Aprendizagem de } \\
\text { conteúdo }\end{array}$ & $\begin{array}{l}\text { - Quanto mais } \\
\text { interdisciplinar a } \\
\text { aula, maior o } \\
\text { aprendizado, as } \\
\text { aprovações no Enem } \\
\text { e a relação com o } \\
\text { cotidiano dos alunos; } \\
\text { - É importante para } \\
\text { o professor também. }\end{array}$ & $\begin{array}{l}\text { Prof. 1: "A } \\
\text { interdisciplinaridade } \\
\text { influencia no contexto } \\
\text { histórico do aluno, na sua } \\
\text { visão política e social } \\
\text { de determinados assuntos } \\
\text { e isso reflete na sua } \\
\text { formação". } \\
\text { Prof. 2: "Trabalhando } \\
\text { interdisciplinarmente com } \\
\text { outros professores, o } \\
\text { professor acaba } \\
\text { aprendendo sobre a área } \\
\text { do outro e isso é refletido } \\
\text { na aprendizagem dos } \\
\text { alunos". } \\
\text { Prof. 3: "O trabalho } \\
\text { interdisciplinar } \\
\text { proporciona uma maior } \\
\text { interação entre as } \\
\text { disciplinas facilitando o } \\
\text { aprendizado do aluno". }\end{array}$ \\
\hline
\end{tabular}




\begin{tabular}{|c|c|c|c|}
\hline $\begin{array}{l}\text { Qualidade de ensino } \\
\text { e TC }\end{array}$ & $\begin{array}{l}\text { Ferramenta } \\
\text { Disciplinar }\end{array}$ & $\begin{array}{l}\text { - Melhora a postura } \\
\text { do aluno na sala de } \\
\text { aula e sua } \\
\text { convivência em } \\
\text { grupo, respeito ao } \\
\text { próximo, contribui } \\
\text { na formação quanto } \\
\text { cidadão. }\end{array}$ & $\begin{array}{l}\text { Prof. 1: "O TC significa } \\
\text { para o aluno } \\
\text { amadurecimento já que } \\
\text { ele aprende a conviver em } \\
\text { grupo, e pode melhorar } \\
\text { nas apresentações de } \\
\text { trabalhos". } \\
\text { Prof. 2: "É uma } \\
\text { ferramenta que educa, } \\
\text { pois eles aprendem a } \\
\text { respeitar o próximo, } \\
\text { cumprir horários, se } \\
\text { esforçar para aprender os } \\
\text { conteúdos, além de mudar } \\
\text { seu comportamento fora } \\
\text { da escola". } \\
\text { Prof. 3: "O aluno } \\
\text { desenvolve habilidades } \\
\text { além do aprendizado, } \\
\text { como o respeito pelos } \\
\text { colegas e as } \\
\text { responsabilidades com o } \\
\text { grupo". }\end{array}$ \\
\hline
\end{tabular}




\begin{tabular}{|c|c|c|c|}
\hline CATEGORIA & SUBCATEGORIA & $\begin{array}{c}\text { UNIDADE DE } \\
\text { REGISTRO }\end{array}$ & $\begin{array}{l}\text { UNIDADE DE } \\
\text { CONTEXTO }\end{array}$ \\
\hline $\begin{array}{l}\text { Abordagens } \\
\text { interdisciplinares no } \\
\text { TC e suas } \\
\text { dificuldades }\end{array}$ & Dificuldades & $\begin{array}{l}\text { - Música, fatos } \\
\text { históricos, temas } \\
\text { atuais da sociedade } \\
\text { e política, } \\
\text { compreensão e } \\
\text { produção de texto, } \\
\text { poesia, etc. }\end{array}$ & $\begin{array}{l}\text { Prof. 1: "Procuramos } \\
\text { sempre abordar temas } \\
\text { considerados importantes } \\
\text { no contexto da sociedade, } \\
\text { e sempre inovar com } \\
\text { outras áreas através da } \\
\text { música, dança, história e } \\
\text { até do direito". } \\
\text { Prof. 2: "Alguns } \\
\text { professores acham o } \\
\text { projeto interessante, } \\
\text { mas na hora que } \\
\text { procuramos a colaboração } \\
\text { deles, eles se esquivam e } \\
\text { falam que não tem tempo, } \\
\text { ou que nunca trabalharam } \\
\text { com isso antes. Acho que } \\
\text { não querem sair da sua } \\
\text { zona de conforto, ou } \\
\text { realmente não sabem } \\
\text { como podem ajudar". } \\
\text { Prof. 3: "Não tivemos } \\
\text { uma formação } \\
\text { interdisciplinar, por isso } \\
\text { temos muitas dificuldades } \\
\text { em trabalhar essa } \\
\text { prática". }\end{array}$ \\
\hline
\end{tabular}

Fonte: Elaborado pelos autores.

Observando o quadro e o contexto das respostas dos professores, percebeu-se que, tratando-se de qualidade de ensino, ainda há o pensamento de que a qualidade está relacionada com notas avaliativas e aprendizagem de conteúdo focadas principalmente nos resultados 
do Enem e vestibulares, como relatado logo no início do quadro com a fala dos Prof. 1 e Prof. 3 quando exaltam os resultados do Enem. Paro (2007) discute sobre a qualidade de ensino, ressaltando a importância da formação do cidadão, por meio de valores e pensamentos críticos. Nesse sentido, a fala do Prof. 2 se faz condizente com esse pensamento quando ele traz, em seu relato, o entendimento de que tal qualidade se trata também da formação do aluno enquanto cidadão, visto que é importante que ele saiba utilizar esses conhecimentos em tomadas de decisões. Paro (2007) também discute a importância destas expectativas de futuro que o aluno adquire pela qualidade de ensino. $\mathrm{O}$ autor vê uma relação dessa qualidade com as escolhas dos alunos após o ensino médio (PARO, 2007).

Quando se vê o aluno interessar, no ensino médio, pela pesquisa, por uma área de interesse profissional, decidindo e almejando uma graduação e uma profissão, percebe-se o quanto a qualidade de ensino foi significativa. Percebe-se também a importância que os docentes dão para o envolvimento dos familiares e da comunidade como um todo nessa formação dos alunos, como destacado na fala dos Prof. 1 e Prof. 2. Já o Prof. 3 lembra a importância dos projetos acadêmicos desenvolvidos nas escolas como feiras de ciências e outras atividades.

O envolvimento dos alunos nos projetos acadêmicos também é importante, visto que, nessa oportunidade, eles têm a chance de pesquisar mais sobre aquilo que, de certa maneira, lhe interessa ou sanar suas indagações, promovendo o desenvolvimento de pensamentos mais críticos sobre determinados assuntos. Os professores veem o TC como uma ferramenta que auxilia nessa formação, visto que os alunos aprendem a conviver em grupo, debatem temas polêmicos nos textos teatrais, formando um pensamento crítico, adquirem responsabilidades, e tudo isso favorece a formação do cidadão. Saraiva (2007) afirma que essa é uma ferramenta que vai além do ensino, pois é capaz de ampliar esse conhecimento tanto por parte dos alunos envolvidos direta e indiretamente, quanto por parte do público que o assiste (SARAIVA et al., 2007).

Percebeu-se que a prática interdisciplinar é bastante clara para esses professores, visto que todos a entendem como um trabalho coletivo e não como a supremacia de uma disciplina diante das outras, como visto nas falas dos 2 primeiros professores ao serem questionados sobre o que seria interdisciplinaridade. Ambos falam do trabalho em equipe por meio de projetos e aulões, e ainda lembram que, por mais que um professor tente contextualizar utilizando-se de conteúdos de outras disciplinas, isso ainda não é o bastante. Fazenda (2011) ressalta que não existe essa hegemonia, pois todas as ciências são igualmente importantes nesse processo. Os docentes têm consciência que é preciso que os professores queiram em conjunto elaborar e planejar atividades que promovam essa ação e, quando um professor aborda outras disciplinas em sua aula, não se considera atividade interdisciplinar. Japiassu (1976) fala desse trabalho em equipe envolvendo a real integração das disciplinas no âmbito de um único projeto. Porém, no relato do Prof. 3, observa-se que alguns colegas das escolas ainda veem a interdisciplinaridade como uma exigência do Enem, algo obrigatório, que não se sentem motivados a isso. Alguns fazem por determinação da direção da escola, e outros até têm vontade, porém, não têm tempo devido seus outros vínculos empregatícios (FAZENDA, 2011; JAPIASSU, 1976). 
Sabe-se que o trabalho em grupo tem suas dificuldades. Quando se fala em trabalho interdisciplinar entre professores, percebe-se mais dificuldades ainda. Fazenda (2011) discutiu essas dificuldades do trabalho integrado entre professores no livro "Integração e interdisciplinaridade no ensino brasileiro", e traz o fato de que a falta de formação específica referente a tomadas de atitudes no trabalho integrado, gera problemas diante das mudanças propostas pelo grupo que pretende realizá-lo (FAZENDA, 2011).

O que se percebe é que os professores se dizem abertos à proposta interdisciplinar, porém, quando se propõem mudanças no formato ou no contexto disciplinar para uma melhor adaptação interdisciplinar, esses recuam pelo medo de acabarem limitando demais suas disciplinas, ou por medo de não saber, ou dominar a disciplina do colega. Outro fator que pode influenciar é simplesmente a falta de interação entre os professores. Silva e Rodrigues (2009) relatam essa consideração nos resultados de seus estudos, no qual os professores abordam ser perceptível a falta de sintonia entre os pares de áreas distintas no planejamento anual. Sabe-se que é comum ver essa realidade nas escolas. Talvez isso ocorra pela falta de preparo e formação para esse tipo de trabalho integrado, como já citado anteriormente. Vale salientar que os professores têm a consciência de que a interdisciplinaridade e a qualidade de ensino estão diretamente ligadas não só à formação do cidadão, mas também à aprendizagem dos conteúdos. Acreditam que ao trabalhar de forma interdisciplinar dois ou mais conteúdos em uma aula, os alunos conseguem perceber uma importância maior desses conteúdos na sua vida, e que isso também pode influenciar na formação de suas opiniões relacionadas a determinados assuntos. Isso reflete a afirmação de Fazenda (2011), quando destaca que a interdisciplinaridade proporciona um conhecimento menos fragmentado, transformando-o no conhecimento unitário, ou seja, o aluno passa a ver os conhecimentos como um só. (SILVA; RODRIGUES, 2009)

Tratando-se da abordagem interdisciplinar no TC e suas dificuldades, percebe-se o esforço para que essas abordagens ocorram, por meio da música, dos fatos históricos, do uso contínuo do português na escrita dos textos, das pesquisas geográficas, biológicas e outros, como mencionado pelo Prof. 1. Porém, percebeu-se também que esse esforço acontece de forma unilateral, visto que eles não recebem apoio dos professores dessas áreas na construção dessas abordagens, como citado pelo Prof. 2. Lopes (2005) afirma que há interdisciplinaridade simplesmente pelo fato de haver a proposta e a busca por essas abordagens. Porém, entende-se que essa prática acaba sendo prejudicada devido à falta de participação dos demais professores, seja por falta de tempo ou interesse. Quanto às dificuldades, o Prof. 2 relata o comodismo dos demais colegas que acreditam que não devem sair da sua zona de conforto porque não vão receber remuneração extra para isso, ou porque já fazem seu papel, que é ensinar. Silva e Rodrigues (2009) citam, em seu trabalho, as mesmas dificuldades e afirmam que a falta de tempo e recurso, ausência de interação entre os professores nos planejamentos e o trabalho solitário pedagógico são vivências comuns no cotidiano escolar. Ou seja, esses relatos sempre estiveram presentes nas pesquisas. Percebe-se que ainda falta um pouco para que esse problema seja sanado. Isso se deve, talvez, à falta de formação como relatado pelo Prof. 3, ao mencionar a falta de formação interdisciplinar para justificar não só a sua falta de prática, mas também dos seus colegas. Klei- 
man e Morais (1999) afirmam que há essa insegurança devido à formação dos professores ter se dada de forma compartimentada. Segundo o $3^{\circ}$ professor, ao ouvir o pedido para ajudar na orientação do TC com alguns temas relacionados às suas disciplinas, os professores falam que não têm tempo ou que nunca trabalharam com TC e não sabem como ajudar, ou seja, percebe-se também certa falta de interesse em conhecer e contribuir com o projeto (LOPES, 2005; SILVA; RODRIGUES, 2009; KLEIMAN; MORAES, 1999).

\section{CONSIDERAÇÕES FINAIS}

Em todo o contexto da pesquisa, desde os estudos bibliográficos até a conclusão com as entrevistas com os professores, percebeu-se a importância que as práticas interdisciplinares têm e como elas podem influenciar na qualidade de ensino. Na visão dos professores, ambas estão diretamente ligadas à formação dos alunos não só no sentido de conteúdo, que é refletido nos resultados do Enem e outras avaliações, mas também na formação do aluno enquanto cidadão.

Sobre a prática interdisciplinar em si, percebe-se que se tem ainda um longo caminho a percorrer, visto que ainda hoje se percebe, nas formações de licenciaturas, uma formação muito compartimentalizada, que acaba fazendo alguns professores terem medo de se "aventurar" em tais práticas. O TC é visto por eles como uma ferramenta interdisciplinar que amplifica essa qualidade de ensino por meio das abordagens não só da ciência, mas também de outras disciplinas, como história, artes, geografia, biologia e outras. Também percebem que a cobrança de responsabilidades e respeito mútuos que um trabalho em grupo exige e do "amadurecimento" das ideias e opiniões críticas que esses adquirem, nos debates e nos textos teatrais, são de fundamental importância para essa formação. Por meio de um texto didático, é possível não só ensinar, ou despertar um interesse pela ciência, como também estimular a liberdade intelectual dos alunos, considerando-se a abordagem de temas políticos, sociais, culturais, filosóficos e outros, unindo a ciência com fatos reais do cotidiano dos alunos ou da sociedade como um todo. Apesar dos benefícios que essa ferramenta traz para o ensino, não é fácil aplicar um projeto assim nas escolas, visto que o apoio dos demais professores é pouco não só no TC, mas também em qualquer atividade que seja interdisciplinar. Essa falta de apoio não pode ser vista com um empecilho, pois, somente pelo fato de haver a iniciativa dos professores, já se considera um passo. Também não se pode esquecer de que, apesar desta atividade ser um tanto questionada por alguns professores por considerar o uso do lúdico no ensino de ciências, "uma brincadeira", Moreira (2013, p. 155) deixa bem claro que esta é uma atividade séria, pois "nos teatros com temática científica, além da preocupação artística há a preocupação com a informação científica, assim a liberdade poética termina por ser limitada pela necessidade de clareza e precisão da comunicação da informação científica". Sendo assim, o TC não minimiza o lado pedagógico e educativo, pelo contrário, a metodologia é baseada nesses dois parâmetros (MOREIRA, 2013). 


\section{REFERÊNCIAS}

BARDIN, L. Análise de conteúdo. Lisboa: Edição 70, 1997.

BARDIN, L. Análise de conteúdo. $2^{\circ}$ reimp. 1. ed. São Paulo: Edição 70, 2011.

BOGDAN, R. C. et al. Investigação qualitativa em educação: uma introdução à teoria e aos métodos. Coleção ciências da educação. Porto: Editora Porto, 1994.

FAZENDA, I. C. A. Interdisciplinaridade: história, teoria e pesquisa. 10. ed. Campinas: Papirus editora, 2002.

FAZENDA, I. C. A. Integração e interdiciplinaridade no ensino brasileiro: efetividade ou ideologia? 6. ed. São Paulo: Edições Loyola, 2011.

FRANCISCO JUNIOR, W. E. et al. O teatro científico como ferramenta para a formação docente: uma pesquisa no âmbito do pibid. Revista Brasileira de Pesquisa em Educação em Ciências, v. 14, n. 3, p. 79-100, 2014.

FREIRE, P. Pedagogia da autonomia: saberes necessários à prática educativa. 25. ed. São Paulo: Paz e Terra, 2002.

GARCEZ, E. S. C. et al. O lúdico em ensino de química: um estudo do estado da arte. 2014. Dissertação (Mestrado em Educação em Ciências e Matemática) - Universidade Federal de Goiás, Programa de Pós-Graduação em Educação em Ciências e Matemática, Goiânia, GO, Brasil, 2014.

GODOY, A. S. Pesquisa qualitativa: tipos fundamentais. Revista de Administração de empresas, SciELO Brasil, v. 35, n. 2, p. 20-29, maio/Jun. 1995.

JAPIASSU, H. Interdisciplinaridade e patologia do saber. Rio de Janeiro: Editora Imago, 1976.

KLEIMAN, A. B.; MORAES, S. E. Leitura e interdisciplinaridade: tecendo redes nos projetos da escola. Campinas: Mercado de Letras, 1999.

LOPES, A. C. Discursos curriculares na disciplina escolar química. Ciência \& Educação, Universidade Estadual Paulista, v. 11, n. 2, p. 263-278, 2005.

LOPES, A. C.; MACEDO, E. Teorias de currículo. São Paulo: Editora Cortez, 2011.

LÜCK, H. Pedagogia interdisciplinar: fundamentos teórico-metodológicos. Petrópolis: Vozes, 1994.

LUDKE, M.; ANDRÉ, M. E. D. A. Pesquisa em educação: abordagens qualitativas. São Paulo: Editora EPU, 1986.

MORAN, J. M.; MASETTO, M. T.; BEHRENS, M. A. Novas tecnologias e mediação pedagógica. 10. ed. Campinas: Papirus Educação, 2000.

MOREIRA, L. M. O teatro em museus e centros de ciências: uma leitura na perspectiva da Alfabetização Científica. 2013. Tese (Doutorado em Educação) - Universidade de São Paulo, Programa de Pós-graduação em Educação, São Paulo, SP, Brasil, 2013. 
MOREIRA, L. M.; MARANDINO, M. O teatro científico na perspectiva da alfabetização científica. In: IX Encontro Nacional de Pesquisa em Educação em Ciências - IX ENPEC. Águas de Lindóia, SP: NUTES, 2013.

MOREIRA, L. M.; REZENDE, D. B. O jogo teatral nos processos de ensino e aprendizagem em ciências: um estudo de caso. In: VI Encontro Nacional de Pesquisas em Educação em Ciências - XI ENPEC. Águas de Lindóia, SP: NUTES, 2007.

PARO, V. H. Gestão escolar, democracia e qualidade do ensino. São Paulo: Ática, 2007.

SANTOS, W. L. P. A química e a formação para a cidadania. año internacional de la química (divulgación de la química). Educación química, v. 22, n. 4, p. 300-305, 2011.

SANTOS, W. L. P.; MORTIMER, E. F. A dimensão social do ensino de química - um estudo exploratório da visão de professores. In: II Encontro Nacional de Pesquisa em Educação Em Ciências. Valinhos: FEP, 1999.

SARAIVA, C. C. et al. Teatro científico e ensino da química. 2007. Dissertação (Mestrado em Química) - Universidade do Porto, Programa de Pós-graduação em Química, Porto, 2007.

SILVA, O. S.; RODRIGUES, M. A. A interdisciplinaridade na visão de professores de química do ensino médio: concepções e práticas. In: Encontro Nacional de Pesquisa em Educação em Ciências - VII ENPEC. Florianópolis - BH: POSGRAD, 2009.

TEIXEIRA, E. F. B. Emergência da inter e da transdisciplinaridade na universidade. In: AUDY, J. L. N.; MOROSINI, M. C. (Org.). Inovação e Interdisciplinaridade na Universidade. Porto Alegre: EDIPUCRS, 2007. v. 1, p. 58-90.

THIESEN, J. S. Currículo interdisciplinar: contradições, limites e possibilidades. Revista Perspectiva, Florianópolis, v. 31, n. 2, p. 591-614, maio/ago. 2013. 